\title{
Introdução À Edição Temática Classes Socials, Estado e Desigualdades ${ }^{1}$
}

Marco Natalino²

Felix Lopez ${ }^{3}$

\section{APRESENTAÇÃO}

Esta edição do Boletim de Análise Político-Institucional reúne, em formato de notas de pesquisa, um compêndio de estudos que exploram os dados coletados e organizados no projeto de pesquisa Radiografia do Brasil Contemporâneo, que consistiu em uma pesquisa qualitativa de grande escala, realizada em 2015 e 2016 pelo Ipea (Visser, 2015; Natalino e Visser, 2017). O principal substrato empírico da pesquisa é composto de entrevistas semiestruturadas, em profundidade, com 632 brasileiros adultos, residentes em áreas urbanas de todas as regióes do país. As mais de cinquenta laudas, em média, de cada entrevista transcrita, narram histórias de vida de pessoas entremeadas pela sua relação com instituiçóes econômicas, sociais e políticas. Essas relações com o trabalho, a escola, a religião, a família e o Estado se entrecruzam de forma significativa e revelam o sentido dado pelo indivíduo a cada uma dessas instituiçóes no seu percurso de vida. Buscou-se, assim, captar processos de formação de classes sociais e reprodução de desigualdades, compreendendo-os à luz das disposiçóes práticas, dos modos de vida e das visôes de mundo da população.

O roteiro utilizado ${ }^{4}$ assemelha-se, em seu conteúdo, a um tipo de enquete comum às pesquisas de mobilidade social, em que a origem de classe é captada e confrontada com o atual status. Dessa forma, a primeira parte das entrevistas versa sobre temas clássicos, como origem familiar, escolaridade, ocupação, renda e consumo. Tais temáticas são como um fluxo narrativo em que o entrevistado revisita a sua primeira infância; o nível educacional e a situação ocupacional dos pais; a relação com familiares, vizinhos e outras redes sociais de apoio; sua vivência com o mundo escolar; a transição entre a escola e o trabalho; a trajetória ocupacional; e os hábitos de poupança e consumo. Percepções sobre a relação entre o indivíduo, a sociedade e o Estado ocupam, grosso modo, outra parte das entrevistas, na qual noçôes de bem-estar, nação, justiça, desigualdade e política são entremeadas com experiências de leitura, fontes de informação, práticas religiosas, meios de engajamento social e formas de acesso a serviços públicos. Em todos os casos, captaram-se não apenas os fatos, mas também os sentidos atribuídos, pelas pessoas, às suas açôes e ao seu contexto.

Em comparação com esse gênero de enquete, a pesquisa inova em dois quesitos. Primeiro, a extensão do roteiro de pesquisa é maior que em uma enquete tradicional, o que permitiu abordar a esfera da cidadania e seus significados. Segundo, ao evitar-se a formatação de uma estrutura rígida de perguntas e respostas, criou-se espaço para capturar a interpretação contemporânea das visôes de Estado e democracia dos brasileiros. A "opinião pública" captada expressou-se de forma aberta, apresentando um quadro de cogniçôes, valores e preferências mais acurado que o possibilitado por meio da aplicação de questionários fechados, e muito mais amplo e heterogêneo que o almejado por pesquisas qualitativas de pequena escala.

1. DOI: http://dx.doi.org/10.38116/bapi23introduçao

2. Especialista em políticas públicas e gestão governamental na Diretoria de Estudos e Políticas Sociais (Disoc) do Ipea.

3. Técnico de planejamento e pesquisa na Diretoria de Estudos e Políticas do Estado, das Instituições e da Democracia (Diest) do Ipea.

4. Encontra-se no anexo desta introdução. 
Uma motivação central deste projeto foi apurar: i) a maneira pela qual a ação do Estado atua concretamente na vida dos entrevistados; e ii) o modo como essa ação, em sua pluralidade, é interpretada por diferentes segmentos sociais. Os estudos que compóem esta edição deixam claro que as experiências e as percepções expressas não são aleatoriamente distribuídas, sendo condicionadas pelos espaços de socialização e pela posição de classe das pessoas.

A (des)conexão entre as intençóes manifestadas pelos agentes do Estado e a cidadania não deve ser menosprezada: é comum uma política pública ser arquitetada com base em juízos preconcebidos sobre o público-alvo a ser atendido. Isso se reverte em pressupostos irreais acerca das demandas de quem necessita de atenção pública e de quais são suas expectativas em termos de justiça, participação e direitos. A chance de desconexão é maior quando as origens de classe e os mundos sociais em que habitam formuladores, implementadores e público-alvo são tão diferentes.

Compreender as condiçóes e as expectativas de vida dos cidadãos possibilita que determinados desenhos de política possam ser reavaliados quanto a sua demanda, seus modos de operação e suas entregas. O material que começa a ser explorado aqui ambiciona contribuir para um entendimento institucional e político mais congruente com a realidade de vida da população brasileira. Para isso, é preciso tanto adentrar a vocação oficial de Estado em suas esferas de atuação quanto entender suas possibilidades de legitimação pública e reformulação a partir das condiçóes sociais e econômicas, dos limites e capacidades, do público beneficiário e potencial.

\section{CLASSES SOCIAIS NO BRASIL CONTEMPORÂNEO}

A pesquisa Radiografia do Brasil Contemporâneo se insere no debate suscitado a respeito das implicaçóes sociológicas do amplo movimento de ascensão social observado por uma parcela significativa dos brasileiros a partir do início dos anos 2000. De 2003 a 2014, 32 milhóes de brasileiros saíram da condição de miséria e outros 30 milhóes deixaram a condição de pobreza. Esse contingente representa quase um terço da população brasileira (Singer, 2018, p. 78).

A pesquisa contemplou cinco classes sociais, denominadas "ralé estrutural" "batalhadores", "classe média", "classe média alta" e "classe alta", as quais foram construídas a partir de investigaçóes anteriores acerca da estrutura social brasileira (Souza, 2009; 2012). Buscou-se ampliar o campo de investigação do foco original nas fraçóes da classe trabalhadora em condição de pobreza, vulnerabilidade e ascensão social recente - esta última pelo menos até 2014 - para incorporar as camadas "estabelecidas" da estrutura social. Em todos os casos, a indicação da classe do entrevistado foi resultado de entrevistas em profundidade com cada um, em que relataram sua origem e sua condição social em termos de capital econômico, cultural e social, considerando-se ainda a ocupação, os gostos e os repertórios políticos e morais.

A ralé estrutural pode ser entendida como a fração inferior da classe trabalhadora, ou, em termos clássicos, como os lumpemproletários, desclassificados, marginalizados, pobres. São particularmente vulneráveis à violação de direitos e reproduzem-se intergeracionalmente como classe excluída. A pesquisa revela que advêm de um ambiente familiar e comunitário de baixíssimo capital econômico e cultural, marcado por pobreza, instabilidade dos cuidados familiares e frágil estímulo ao desenvolvimento infantil. Possuem baixo ou baixíssimo patrimônio, reduzido capital social e escolaridade ou até mesmo, no caso de seus membros mais velhos, nenhuma instrução formal. Na esfera da produção, inserem-se como trabalhadores elementares, empregados domésticos e autônomos precários. Sua capacidade de venda da força de trabalho é bastante limitada, auferindo salários em média próximos ao mínimo. A ralé é, 
geralmente, desfiliada do sistema de seguro social, e, quando se filia à força de trabalho formal, permanece por pouco tempo nessa condição. Sua trajetória laboral é marcada, assim, pelo risco do desemprego, da doença e da incapacidade ao trabalho.

Os batalhadores constituem uma nova classe trabalhadora, por vezes mal identificada como uma "nova classe média", incluída econômica e culturalmente nos fluxos contemporâneos do sistema capitalista global. ${ }^{5}$ Se a ralé estrutural constitui um grupo "não só sem capital cultural e econômico em qualquer medida significativa, mas desprovida (...) das precondiçóes sociais, morais e culturais que permitem essa apropriação" (Souza, 2009, p. 21), os batalhadores constituem uma classe que, de forma limitada, tem algum capital econômico e cultural, bem como uma espécie de "capital familiar" (Souza, 2012; Menezes, 2018) que se expressa como uma disposição prática para o agir no mundo adaptado à ética do trabalho contemporânea. $\mathrm{O}$ pensamento prospectivo, o autocontrole e a disciplina permitem uma inclusão subordinada no mundo da produção interditada à ralé, presa que está às necessidades inadiáveis do presente.

As entrevistas revelam que a socialização primária dos batalhadores se deu em ambiente de capital cultural, econômico e social superior à ralé, mas ainda assim relativamente baixo. No que se refere ao capital familiar, nota-se que os estímulos ao desenvolvimento infantil foram significativamente maiores em relação à ralé, e a "criação", por assim dizer, envolveu também mais comunicação e menos violência. Os batalhadores possuem escolaridade média, sendo comum até mesmo o contato com o ensino superior entre seus membros mais novos. Tendem a se inserir na esfera da produção, seja como trabalhadores formais qualificados e supervisores, seja como trabalhadores autônomos, por conta própria, geralmente em condiçóes precárias, mas podendo até mesmo ser pequenos empregadores. Sua capacidade de venda da força de trabalho, para além da escolaridade e das disposiçóes práticas apontadas, associa-se, por vezes, a um pequeno patrimônio, o que lhes possibilita auferir rendas próximas à mediana nacional.

A classe média são os estabelecidos. Gozam de um relativo privilégio no que se refere à acumulação de capital cultural (principalmente de tipo escolar), capital econômico e prestígio social. Seu privilégio básico se assenta, ainda mais que os batalhadores, sobre poder "esperar e se preparar para o futuro" (Souza, 2012, p. 52), dedicando-se aos estudos a fim de ingressar no mercado de trabalho em condiçóes mais vantajosas.

Os entrevistados dessa classe são pessoas oriundas de famílias com capital cultural e econômico médio, que lhes propiciaram alta estabilidade nos cuidados afetivos, estimularam seu desenvolvimento durante a infância e os criaram mais na base da conversa que no disciplinamento violento. Viveram e vivem em bairros com infraestrutura urbana adequada e socializaram-se em ambientes típicos das classes médias, como as escolas particulares. São pessoas, em geral, com superior completo ou até mesmo alguma pós-graduação, e tendem a possuir algum patrimônio. São empregados especializados, especialistas autoempregados, por vezes assumindo cargos de gerência ou atuando como pequenos empregadores, e auferindo rendimentos muito acima da média nacional.

As classes média alta e alta não são tão facilmente distinguíveis com base na pesquisa. $\mathrm{O}$ motivo principal é o número relativamente baixo de pessoas dessas classes que foram entrevistadas. ${ }^{6} \mathrm{~A}$ distinção mais clara entre elas, como seria de se esperar, está no nível de renda e na propriedade de meios de produção.

5. Para uma síntese de um instigante debate conceitual e terminológico sobre os atributos definidores das frações emergentes da miséria e da pobreza (por exemplo, nova classe média, nova classe trabalhadora e batalhadores, entre outros), remetemos ao capítulo 2 de Singer (2018).

6. Foram entrevistadas 46 pessoas de classe média alta e 14 de classe alta. 
Mais que as classes médias estabelecidas, as classes alta e média alta nasceram e cresceram em famílias de capital cultural e econômico de médio para alto. Suas redes sociais são ricas em recursos e seu patrimônio pessoal é elevado. Para além do nível de escolaridade em si, que é maior, distinguem-se da classe média pela característica elitista das instituiçôes de ensino superior que frequentaram. Se a classe alta é composta principalmente de proprietários e grandes empregadores, a média alta é majoritariamente formada pela combinação de alta especialização e exercício de autoridade no ambiente de trabalho, sendo, com maior frequência que a classe média, "chefes".

Apresentados o contexto e os objetivos do projeto, bem como a perspectiva teórica e empírica de enquadramento das classes sociais, descrevemos a seguir os temas de cada texto da publicação.

\section{OS TEXTOS DA PUBLICAÇÃO}

Sete dos oito artigos que integram esta edição temática utilizam os dados empíricos coletados no projeto Radiografia do Brasil Contemporâneo. Essa unidade se desdobra na diversidade de recortes e exploraçóes dos dados coletados. De modo panorâmico, os textos contribuem para apurar o entendimento das clivagens sociais e de classe da sociedade brasileira, e como tais clivagens se retraduzem em apreciaçóes, repertórios e atitudes das pessoas no entendimento de políticas públicas ou fenômenos sociais, guardando coerência com suas trajetórias e posiçóes no espaço social, ou de classe.

$\mathrm{O}$ artigo de Emerson Rocha, Espaço social e estrutura de classes em regióes metropolitanas brasileiras, contribui para a compreensão da distribuição de atitudes dos brasileiros no espaço social (Bourdieu, 1996; 2007). O texto aplica uma análise de componentes principais a fim de explorar se as escalas atitudinais referentes a esferas de ação social - ao trabalho, à família, à comunidade, à política e ao consumo cultural - revelam estilos de vida próprios em cada classe social. A análise empírica se insere nas discussões sobre a pertinência do conceito de classe e em que medida ele captura de forma heuristicamente útil disposiçóes incorporadas, atitudes e comportamentos. Rocha explora se, entre as classes, distâncias e proximidades na posse de bens materiais correspondem a distâncias e proximidades imateriais.

No artigo Classe, estilos de vida e valores no Brasil, André Vieira e Felix Lopez abordam, de modo preliminar, as possibilidades de testar empiricamente a propriedade do conceito de classe social, entendido e operacionalizado de forma multidimensional, para caracterizar o espaço das disposiçóes comportamentais dos indivíduos em relação às diferentes esferas da ação social. Para tanto, inspirados em Grusky e Weeden (2010), os autores utilizam dados de survey e a técnica de análise de classes latentes com o objetivo de identificar grupamentos emergentes observados a partir de preferências comuns em relação aos hábitos de lazer e aos estilos musicais, bem como atitudes quanto ao ativismo cívico. $\mathrm{O}$ texto dialoga com as intençóes de verificar como a classe social explica aspectos da organização de identidades e estratégias de vida dos brasileiros, e as conexôes entre posições de classe e estilos de vida (Bourdieu, 2007).

Em Encontros burocráticos e suas reverberaçôes simbólicas: uma exploração das experiências de interação cotidiana com agentes do Estado, Roberto Pires aplica a "sociologia do guichê" para analisar as situaçóes em que pessoas interagem com funcionários do governo - os encontros burocráticos. Tais encontros são uma via para acessar os microdispositivos que alimentam a autoimagem que os segmentos sociais produzem de si e dos outros a partir da interação com agentes do Estado. Esses agentes são a face prática das açóes e dos discursos que, na realidade, impóem, reproduzem e dão corpo às categorias oficiais - arbitrárias - do Estado, ao mesmo tempo que manifestam preconceitos sobre diferentes classes de cidadáos, com base em experiências e socializaçóes fora do próprio Estado. Os encontros são, por assim dizer, matrizes geradoras 
de cogniçóes do cidadão sobre o Estado e, nesse sentido, essenciais para compreender a construção cotidiana dos sentidos práticos que o Leviatã e suas políticas carregam no imaginário de distintos públicos das organizaçóes estatais. Em sentido reverso, revelam como os agentes públicos classificam, reclassificam e desclassificam os cidadãos na atividade cotidiana.

No artigo Pobreza, redistribuição e o Programa Bolsa Família na percepção dos brasileiros, Marco Natalino explora as diferenças e as similitudes nas percepçóes das classes sociais sobre o Programa Bolsa Família e, por esse prisma, captura valores e cogniçôes a respeito da pobreza, da desigualdade social, da redistribuição e das avaliaçôes da sociedade civil sobre os beneficiários "merecedores" e "não merecedores" de políticas. A análise aponta as dificuldades de ampliar a cidadania social para setores excluídos em face dos estigmas que lhes são associados. Essas dificuldades se ampliam quando os benefícios sociais mínimos são focalizados apenas nesses grupos e, portanto, não contam com uma coalizão de apoio majoritária, gerando um regime de bem-estar menos generoso e mais desigual (Korpi e Palme, 1998).

Em Repertórios sobre as razóes da desigualdade no Brasil, Felix Lopez explora, a partir das entrevistas, os enquadramentos e os repertórios aos quais os brasileiros recorrem para explicar as razóes das desigualdades que marcam a autoimagem do país. Emergem cinco enquadramentos que reforçam argumentos que atribuem à herança colonial, ao Estado, à corrupção política, à desigualdade educacional e aos atributos individuais as razóes para mantermos o padrão atual de desigualdade.

Antonio Lassance, em $O$ povo não assiste a tudo bestializado, seleciona os fragmentos das entrevistas que revelam as atitudes de diferentes classes sociais do país em relação à mídia corporativa tradicional. Os resultados vão de encontro ao argumento da passividade e internalização acrítica das pessoas em relação às notícias que as alcançam. Embora vivamos sob um conglomerado midiático cujos indicadores comparados apontam riscos para a democracia, não decorre daí - "uma atitude de total passividade, conformismo e bestialização das classes em geral", pois as pessoas reagem de modo seletivo e pragmático às informações que lhes chegam, ainda que o consumo das informaçóes, e os meios de acesso, varie entre classes.

No artigo $A$ meritocracia e a reprodução da desigualdade: análise comparativa entre trajetórias sociais de agentes do campo jurídico, Mariana Garcia sintetiza resultados preliminares da análise sobre as trajetórias dos bacharéis de direito provenientes de diferentes (fraçóes de) classes. A inserção da classe média alta nas posiçôes mais prestigiosas do campo jurídico estatal - as melhores carreiras, os melhores salários e o maior status - espelha desigualdades que vão se estabelecendo na trajetória de vida dos formados provenientes das diferentes classes, na graduação, e como egressos. A ampliação do acesso aos bacharelados de direito - ensejados por políticas de inclusão - e à primeira universidade aos mais pobres - casos do Programa Universidade para Todos (Prouni) ou do Programa de Financiamento Estudantil (Fies) -, paradoxalmente, revelou com maior clareza as condiçóes desiguais da disputa para o ingresso em algumas carreiras públicas, embora as desigualdades se mascarem no discurso meritocrático.

Identificar os repertórios de acesso aos empregos mobilizados por desempregados situados em diferentes faixas de escolaridade, e como esses segmentos significam a perda e a busca por emprego, é o objetivo da análise de Vitor Menezes no texto Perfis educativos e repertórios de acesso a empregos. De fato, segmentos mais e menos escolarizados mobilizam estratégias, repertórios e léxicos essencialmente distintos, que retraduzem os diferentes níveis de instabilidade e incerteza experimentados por cada grupo. 


\section{CONCLUSÃO}

Os textos aqui reunidos contribuem para entendermos algumas das mais importantes clivagens sociais no país e, seja adotando novas metodologias, seja incorporando novos ângulos de análise, aprofundam a compreensão de fenômenos amplos e multidimensionais. Esse é o caso das desigualdades sociais e como elas são percebidas, explicadas e reproduzidas, seja na interação face a face entre o burocrata do balcão e o cidadão, seja nos canais de ascensão ao topo das carreiras jurídicas, seja nos repertórios de justificação ou negação de direitos básicos de cidadania, seja, ainda, nas estratégias de reinserção do mercado de trabalho.

Esta edição temática do Boletim de Análise Politico-Institucional também contribui para apontar novas possibilidades de compreender clivagens sociais e de classe, do ponto de vista metodológico e analítico. Como resultado inicial de um trabalho coletivo de exploraçáo de dados originais e fecundos, espera-se que as análises sintéticas e seus dados empíricos sejam fontes de estímulo para novas explorações, no atual contexto em que divisóes e polaridades entre segmentos e classes se revigoram no país.

\section{REFERÊNCIAS}

BOURDIEU, P. Espaço social e espaço simbólico. In: Campinas: Papirus, 1996.

. Razóes práticas: sobre a teoria da ação.

. O espaço social e suas transformaçóes. In:

A distinção: crítica social do julgamento.

São Paulo: Edusp; Porto Alegre: Zouk, 2007.

GRUSKY, D.; WEEDEN, K. Are there social classes? A framework for testing sociology's favorite concept. In: LAREAU, A.; CONLEY, D. (Ed.). Social class: how does it work? New York: Russell Sage, 2010. p. 65-89.

KORPI, W.; PALME, J. The paradox of redistribution and strategies of equality: welfare state institutions, inequality, and poverty in the western countries. American Sociological Review, v. 63, n. 5, 1998.

MENEZES, V. Família e posiçáo de classe: a socialização familiar pela privação e a socialização familiar protetiva. Brasília: Ipea, 2018. (Texto para Discussão, n. 2379). Disponível em: <http://repositorio.ipea. gov.br/handle/11058/8350>.

NATALINO, M.; VISSER, R. Relatório da pesquisa Radiografia do Brasil Contemporâneo. Brasília: Ipea, 2017. Mimeografado.

SINGER, A. O lulismo em crise: um quebra-cabeça do período Dilma (2011-2016). Rio de Janeiro: Companhia das Letras, 2018.

SOUZA, J. (Org.). Ralé brasileira: quem é e como vive. Belo Horizonte: Editora UFMG, 2009.

. (Org.). Os batalhadores brasileiros: nova classe média ou nova classe trabalhadora? Belo Horizonte: Editora UFMG, 2012.

VISSER, R. Radiografia do Brasil Contemporâneo. Orientação para a realização das entrevistas. Ipea, 2015. Mimeografado. 


\section{ANEXO}

Com o objetivo de facilitar a compreensão dos leitores acerca dos dados explorados nos artigos desta publicação, este anexo é o roteiro semiestruturado que orientou as entrevistas, as quais resultaram no principal material empírico da pesquisa Radiografia do Brasil Contemporâneo.

\section{QUADRO A.1}

Roteiro de entrevistas, por tema

\begin{tabular}{|c|c|}
\hline Questão & Tema \\
\hline Qual era a profissão dos seus pais? & \multirow{4}{*}{$\begin{array}{l}\text { Condição socioeconômica } \\
\text { de origem }\end{array}$} \\
\hline Como eles conciliavam trabalho e família? & \\
\hline Como era a vida de vocês: muito apertada, mais ou menos, ou viviam com folga? Fale mais sobre isso. & \\
\hline Seus pais estudaram até que série? & \\
\hline Quem cuidava de você? Como cuidava? & \multirow{9}{*}{ Infância } \\
\hline O ambiente na sua casa era tranquilo ou era mais conturbado? Quem mais morava na mesma casa? & \\
\hline Como era a divisão do espaço e das tarefas? & \\
\hline Descreva um dia típico da sua infância. & \\
\hline Quando você fazia algo de errado, como você era punido? & \\
\hline Quais eram as preocupações centrais em termos financeiros? & \\
\hline Faltava alguma coisa em casa? & \\
\hline $\begin{array}{l}\text { Nós sabemos que todas as famílias têm coisas boas e também têm muitos problemas. Quais eram as melhores coisas na } \\
\text { sua família? }\end{array}$ & \\
\hline E quais eram as piores? & \\
\hline A gente sempre herda muitas coisas dos nossos pais. 0 que você herdou do seu pai? & \multirow{7}{*}{$\begin{array}{l}\text { Percepção de mudança } \\
\text { socioeconômica }\end{array}$} \\
\hline O que você herdou da sua mãe? & \\
\hline O que você tentou fazer diferente do seu pai? & \\
\hline 0 que você tentou fazer diferente da sua mãe? & \\
\hline $\begin{array}{l}\text { Olhando para a sua família hoje e para o tempo em que você vivia com seus pais, quais as grandes diferenças que você vê } \\
\text { na maneira de criar os filhos? }\end{array}$ & \\
\hline E na maneira de conviver com o companheiro? & \\
\hline E na sua condição social? & \\
\hline Descreva um dia típico na sua escola quando você estava no primário. & \multirow{10}{*}{ Escolaridade } \\
\hline Teve algum professor do qual você gostou muito? & \\
\hline Você estudava em casa? & \\
\hline Como era isso? & \\
\hline Você fazia alguma atividade além da escola? & \\
\hline Como era isso? & \\
\hline Você se considerava inteligente na escola? Fale mais sobre isso. & \\
\hline E seus pais e professores, em geral, eles te achavam inteligente? & \\
\hline O que você mais gostava de fazer na escola? & \\
\hline E o que você não gostava de fazer? & \\
\hline
\end{tabular}


(Continuação)

\begin{tabular}{|c|c|}
\hline Questão & Tema \\
\hline E quando você ficou adolescente, o que mudou na sua vida escolar? & \multirow{6}{*}{ Transição escola-trabalho } \\
\hline Quando você começou a pensar em uma profissão? & \\
\hline No que a escola te influenciou nisso? & \\
\hline Quando você começou a trabalhar? & \\
\hline Por quê? & \\
\hline Quantos trabalhos diferentes você teve? Conte essa história. & \\
\hline Descreva um dia típico no seu trabalho atual. & \multirow{9}{*}{ Ocupação } \\
\hline Como é a sua relação com seus superiores e colegas? & \\
\hline Qual era o trabalho dos seus sonhos? & \\
\hline Ele tem a ver com seu trabalho atual? & \\
\hline Que tipo de competências ou habilidades o seu trabalho exige? & \\
\hline Como você desenvolveu essas habilidades? & \\
\hline Você está contente com o seu trabalho ou você pretende mudar? & \\
\hline Você tem uma renda estável? & \\
\hline Qual é a frequência de seus rendimentos (semanal, mensal, trimestral...)? & \\
\hline Como você usa seu dinheiro? & \multirow{7}{*}{ Despesa e poupança } \\
\hline Despesas mensais? & \\
\hline Poupança? & \\
\hline Investimento? & \\
\hline Como você organiza esses gastos? & \\
\hline Alguma forma de controle escrito? & \\
\hline Com qual antecedência? & \\
\hline Você tem muitos amigos? & \multirow{5}{*}{ Capital social } \\
\hline Como você os conheceu? & \\
\hline Algum amigo ou conhecido já te deu algum tipo de ajuda que foi importante para sua vida profissional? & \\
\hline Que lugares você frequenta com seus amigos? & \\
\hline 0 que vocês fazem juntos? & \\
\hline Você tem alguma religião? & \multirow{10}{*}{ Religião } \\
\hline Com que frequência você vai aos cultos? & \\
\hline Com que frequência você faz orações fora do culto? & \\
\hline E outras atividades religiosas? & \\
\hline Que atividades você faz na igreja? & \\
\hline Com quem você vai à igreja? & \\
\hline A que tipo de pessoa Deus ajuda? & \\
\hline Como Deus tem atuado na sua vida? & \\
\hline Que coisas você pede a Deus? & \\
\hline Como Deus age nesse mundo? & \\
\hline Geralmente, o que você faz para se divertir ou se distrair? & \multirow{5}{*}{ Lazer } \\
\hline Quando tem tempo livre, prefere ficar em casa ou gosta de sair? & \\
\hline E o que faz nesse tempo? & \\
\hline E onde você geralmente vai? & \\
\hline Esses lugares que você frequenta, conte-me mais sobre eles. & \\
\hline
\end{tabular}


(Continuação)

\begin{tabular}{|c|c|}
\hline Questão & Tema \\
\hline 0 que você mais gosta de comprar? & \multirow{2}{*}{ Consumo } \\
\hline Com que frequência? & \\
\hline Como você se veste? & \multirow{7}{*}{ Cultura } \\
\hline De que tipo de música você gosta? & \\
\hline Cite exemplos. & \\
\hline Quais os últimos filmes a que você assistiu e gostou? & \\
\hline Por que gostou? & \\
\hline Quais os últimos livros que você leu e gostou? & \\
\hline Por que gostou? & \\
\hline Você gosta de cozinhar? Fale mais sobre isso. & \multirow{3}{*}{ Alimentação } \\
\hline Você considera a sua alimentação saudável? & \\
\hline Por quê? & \\
\hline 0 que você faz para cuidar do seu corpo? & \multirow{3}{*}{ Cuidados com o corpo } \\
\hline Malha? & \\
\hline Pratica esportes? & \\
\hline Você bebe? & \multirow{2}{*}{ Álcool } \\
\hline 0 que costuma beber? Cite uma marca. & \\
\hline As mulheres estão se libertando muito rapidamente. Quais são os aspectos negativos e positivos disso? & \multirow{3}{*}{ Gênero } \\
\hline Você acha que homens e mulheres são iguais ou diferentes? Por quê? & \\
\hline Quem você acha que tem mais satisfação sexual, o homem ou a mulher? Por quê? & \\
\hline 0 que é um parceiro ideal? & \multirow{4}{*}{ Relações conjugais } \\
\hline Qual a diferença entre sexo e amor? & \\
\hline É possível manter a paixão num casamento? & \\
\hline 0 que leva a conflitos em um casal? & \\
\hline Como você se enxerga na sociedade? & \multirow{9}{*}{$\begin{array}{l}\text { Percepção de classe e } \\
\text { políticas públicas }\end{array}$} \\
\hline Como você percebe as classes imediatamente acima da sua? & \\
\hline E as classes imediatamente abaixo? & \\
\hline Como você acha que as políticas públicas tratam as pessoas mais pobres? & \\
\hline 0 que é ter uma vida boa no Brasil? & \\
\hline 0 que seria mais importante e menos importante em uma vida boa? & \\
\hline Como se pode alcançar essa vida boa? & \\
\hline Qual é o papel das políticas públicas para alcançar essa vida boa? & \\
\hline Você pode alcançar essa vida boa? & \\
\hline Qual o papel da educação para assegurar essa vida boa? & \multirow{13}{*}{$\begin{array}{l}\text { Papel e acesso a } \\
\text { políticas sociais }\end{array}$} \\
\hline E o papel das cotas? & \\
\hline E o do Pronatec [Programa Nacional de Acesso ao Ensino Técnico e Emprego]? & \\
\hline Como é sua relação com o SUS [Sistema Único de Saúde]? & \\
\hline Como você o avalia? & \\
\hline E o do Mais Médicos? & \\
\hline E o do Bolsa Família? & \\
\hline E o do Minha Casa Minha Vida? & \\
\hline E você foi ou é beneficiado por algum desses programas? & \\
\hline E como foi essa experiência? & \\
\hline Você foi bem tratado pelos funcionários desses programas? & \\
\hline E você já tentou ser beneficiado e não conseguiu? & \\
\hline E como foi essa experiência de não conseguir? & \\
\hline
\end{tabular}


(Continuação)

\begin{tabular}{|c|c|}
\hline Questão & Tema \\
\hline 0 que seria bem-estar para você? & \multirow{6}{*}{$\begin{array}{l}\text { Bem-estar e projeto } \\
\text { de vida }\end{array}$} \\
\hline Pensando no bem-estar da sociedade, como você vê o papel das políticas sociais? & \\
\hline O que seria para você progresso? & \\
\hline E o que você acha que dificulta a melhora de vida das pessoas? & \\
\hline Você tem algum sonho ou projeto futuro que quer alcançar? & \\
\hline Como você acha que poderia alcançar esse sonho? & \\
\hline Para você, qual é o principal problema do Brasil? Por quê? & \multirow{2}{*}{ Problemas nacionais } \\
\hline 0 que podemos fazer para superá-lo? & \\
\hline Você acha que o preconceito é um problema no Brasil? & \multirow{5}{*}{$\begin{array}{l}\text { Preconceito e } \\
\text { discriminação }\end{array}$} \\
\hline Você já sofreu algum preconceito? & \\
\hline Se sim, poderia contar como foi? & \\
\hline Você acha que há preconceito entre as classes? Por exemplo, entre ricos e pobres? Por quê? & \\
\hline E você acha que as políticas públicas tratam as pessoas de forma humilhante? Por quê? & \\
\hline Como você enxerga a questão do aborto? & \multirow{3}{*}{$\begin{array}{l}\text { Direitos reprodutivos } \\
\text { e sexualidade }\end{array}$} \\
\hline E do casamento gay? & \\
\hline Como você reagiria se alguém próximo se envolvesse em alguma destas questões? & \\
\hline Em qual extensão a questão ambiental impacta a sociedade e a sua vida? & \multirow{4}{*}{$\begin{array}{l}\text { Solidariedade e } \\
\text { engajamento social }\end{array}$} \\
\hline E a desigualdade social? & \\
\hline $\begin{array}{l}\text { Você se engajaria preferencialmente em causas ambientais, maus-tratos de animais, ou em causas "sociais", como } \\
\text { assistência aos usuários de crack ou outros excluídos? (Fazer o entrevistado falar espontaneamente.) }\end{array}$ & \\
\hline Como você percebe isso? & \\
\hline De todas as fontes de informação, em qual você mais confia? Por quê? & \multirow{2}{*}{ Fontes de informaç̧ão } \\
\hline E em qual você menos confia? Por quê? & \\
\hline O Brasil é um país muito desigual. Quais são as causas disso? & $\begin{array}{l}\text { Causas da } \\
\text { desigualdade }\end{array}$ \\
\hline Você é a favor ou contra a maioridade penal? Por quê? & \multirow{4}{*}{$\begin{array}{l}\text { Drogas e } \\
\text { segurança pública }\end{array}$} \\
\hline Você acha que drogas mais leves, como a maconha, deveriam ser descriminalizadas? & \\
\hline E drogas mais pesadas? Por quê? & \\
\hline Como é que o governo deveria lidar com os usuários de crack? & \\
\hline 0 que você acha do ex-presidente Fernando Henrique Cardoso? & \multirow{2}{*}{ Política } \\
\hline E do ex-presidente Lula? Por quê? & \\
\hline
\end{tabular}

Fonte: Pesquisa Radiografia do Brasil Contemporâneo. 